\title{
Comparison of satisfaction with current prosthetic care in veterans and servicemembers from Vietnam and OIF/OEF conflicts with major traumatic limb loss
}

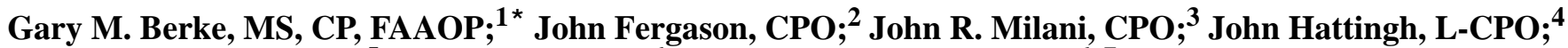 \\ Martin McDowell, CPO; ${ }^{5}$ Viet Nguyen, $\mathrm{MD} ;{ }^{6}$ Gayle E. Reiber, PhD, MPH ${ }^{6-7}$ \\ ${ }^{1}$ Private Practice, Adjunct Clinical Instructor, Stanford University, Redwood City, CA; ${ }^{2}$ Prosthetics-Orthotics Clinic, \\ Brooke Army Medical Center, Fort Sam Houston, TX; ${ }^{3}$ Clinical Manager, Department of Veterans Affairs (VA) Central \\ Office, Prosthetics and Clinical Logistics Office, Washington, DC; ${ }^{4}$ Northwest Prosthetic and Orthotic Clinic, Seattle, \\ WA; ${ }^{5}$ Prosthetic/Orthotic Laboratory, VA Puget Sound Health Care System, Seattle, WA; ${ }^{6}$ University of Washington \\ School of Medicine, Seattle, WA; ${ }^{7}$ Health Services Research and Development Service, VA Puget Sound Health Care \\ System, Seattle, WA
}

\begin{abstract}
Prosthetic care is a vital aspect of healthcare and rehabilitation for veterans and servicemembers with major traumatic limb loss. Our survey queried 581 veterans and servicemembers with limb loss from the Vietnam and Operation Iraqi Freedom (OIF)/Operation Enduring Freedom (OEF) conflicts. Among survey participants, $78.2 \%$ from the Vietnam conflict and $90.5 \%$ from the OIF/OEF conflict currently use prosthetic devices. In Vietnam respondents, 78\% received prosthetic care from private sources, $16 \%$ from Department of Veterans Affairs (VA) prosthetic laboratories, $0.9 \%$ from Department of Defense (DOD), and 5\% from multiple sources. In OIF/OEF respondents, $42 \%$ received prosthetic care from private sources, $9 \%$ percent from VA, 39\% from DOD, and 10\% from multiple sources. Participants identified their satisfaction with current prosthetic devices and prosthetic services. Reports of pain, sweating, skin irritation, and problems with socket fit continue to be significant issues for participants from both conflicts regardless of level of amputation or site of service. In those with upper-limb loss who used myoelectric prostheses, minimal effect on prosthesis use and satisfaction was noted. Among lower-limb loss participants from both conflicts, notable differences existed in prosthesis satisfaction by source of care.
\end{abstract}

Key words: amputation site, OIF/OEF, prosthesis, prosthetic care, prosthetic device, rehabilitation, satisfaction, traumatic limb loss, veteran, Vietnam, wounded servicemember.

\section{INTRODUCTION}

One of the highest priorities for the U.S. Department of Defense (DOD) and Department of Veterans Affairs (VA) is provision of expert rehabilitation care, including prosthetic services, for veterans and servicemembers who suffered major traumatic limb loss in combat zones. The goal of prosthetic rehabilitation is to maximize function and quality of life [1]. Servicemembers from recent conflicts in Iraq and Afghanistan (Operation Iraqi Freedom/Operation Enduring Freedom [OIF/OEF]) typically receive state-ofthe-art rehabilitation and prosthetic care from three major DOD sources: Walter Reed Army Medical Center, Brooke Army Medical Center, and Naval Medical Center San Diego. Some DOD prosthetic services are also provided by

Abbreviations: DOD $=$ Department of Defense, OIF/OEF = Operation Iraqi Freedom/Operation Enduring Freedom, VA = Department of Veterans Affairs.

* Address all correspondence to Gary M. Berke, MS, CP, FAAOP; 801 Brewster Ave, Suite 270, Redwood City, CA 94063; 650-365-5861; fax: 650-365-5896.

Email: gmberke@gmail.com

DOI:10.1682/JRRD.2009.12.0193 
private contractors within DOD facilities. Prosthetic prescriptions for Active Duty servicemembers are developed in a multidisciplinary clinic with input from multiple professional services. Prescriptions are based on demonstrated participation in reaching rehabilitation goals, and specialty limbs are considered to augment participation in activities that can be tied to rehabilitation goals.

Many OIF/OEF servicemembers and all Vietnam veterans have transitioned from DOD to VA. Almost all now receive prosthetic care directly from VA or from private providers under contract with VA. There are 61 large VA medical centers with credentialed VA prosthetists providing in-house prosthetic services [2-3]. In other areas, veterans are first seen within the VA system where they are linked to local credentialed and contracted prosthetic providers with specific prosthetic prescriptions.* Veterans retain the right to choose between private VAfunded prosthetic contractors and receiving prosthetic services from a VA laboratory.

Our recent national Survey for Prosthetic Use (Appendix 1, available online only) queried Vietnam and OIF/ OEF veterans and servicemembers with major combatassociated limb loss. One of the goals of the survey was to determine who used prostheses, the location where they received prosthetic care, what services were received, and their satisfaction with prostheses and prosthetic servicesan increasingly important healthcare quality measure [1]. While changes in surgical techniques, rehabilitation processes, technology, and new materials may contribute to differences in prosthetic satisfaction between Vietnam and OIF/OEF participants, the extent to which these have improved veterans' and servicemembers' prosthetic-device satisfaction has not been evaluated. Therefore, the purpose of this article was to evaluate the experience and satisfaction with prostheses and prosthetic services for Vietnam and OIF/OEF participants with major traumatic limb loss.

\section{METHODS}

Participants in this study were 298 veterans from the Vietnam conflict and 283 servicemembers and veterans

*Eckrich, Neal. (National Program Director, Prosthetic and Sensory Aids Service, VA Central Office, Washington, DC). Personal communication to: Gayle E. Reiber (Program Analyst, Department of Prosthetic and Sensory Aids, VA Puget Sound Health Care System, Seattle, WA). 2009 Mar 16. from the OIF/OEF conflict with major traumatic limb loss who were surveyed during 2007 and 2008. Veterans and servicemembers with major limb loss occurring during the Vietnam (1961-1973) or OIF/OEF (2001-2008) conflicts were invited to participate in a survey on prosthetic use. All servicemembers with major limb loss from OIF/ OEF, all Vietnam veterans with unilateral upper-limb loss and multiple limb loss, and a sample of Vietnam veterans with unilateral lower-limb loss were invited to participate. Servicemembers from OIF/OEF had to be at least 1 year from limb loss. Participants took the survey by one of three methods (mail, telephone interview, or Web site). Great care was taken to ensure that the method of survey participation did not affect results. A detailed description of the study methods is found in another article in this issue [4], which will further outline the limitations of methodology, number of participants, and nonrespondent rates. A generic version of the Survey for Prosthetic Use, including both upper- and lower-limb loss sections, is available in Appendix 1 (available online only).

Excluded from this analysis were 65 Vietnam and 27 OIF/OEF servicemembers who abandoned or never used prostheses, including individuals using wheeled mobility. The reasons for abandonment are discussed in separate articles in this issue [5-7]. Of the 233 Vietnam and 256 OIF/OEF participants included in this study, 3 Vietnam participants and 5 OIF/OEF participants had incomplete satisfaction data and thus were excluded. This article presents data from 230 Vietnam and 251 OIF/OEF participants.

The Survey for Prosthetic Use was developed to address key issues for veterans and servicemembers with major upper- and lower-limb loss by a group of rehabilitation and surgery clinicians and researchers. Participants answered questions on health, combat injuries, and site and level of limb loss (unilateral upper limb, unilateral lower limb, and multiple limb). Pain questions included phantom and residual-limb pain, chronic back pain, and pain associated with prostheses. Participants self-reported past and current use of prostheses by prosthesis type from the time of their initial limb loss to the present. They also identified their current source(s) of prosthetic care; overall satisfaction with their current prostheses, ranging from 0 (not at all satisfied) to 10 (completely satisfied); experiences with prosthetic services; the timeliness of prosthetic repair and replacement; and issues with prosthetic sockets, prosthetic fit, comfort, pain, and nuisances. Patients with multiple limb loss and prostheses were asked specific questions regarding each limb and the prosthetic devices used for 
each limb. The survey was reviewed by prosthetic and rehabilitation experts including members of the study Expert Panel for content validity before being piloted on 24 men and women with traumatic or combat-related limb loss. After refinements to the survey questions, the survey was piloted on servicemembers with major traumatic limb loss from the Desert Storm conflict.

We should note that prosthetic satisfaction and overall satisfaction are different measured parameters within this article. Overall satisfaction is a measure of the comprehensive aspects of care: site of service, ability to receive timely appointments, and rehabilitation and prosthetic care. Prosthetic satisfaction is a measure of prosthetic fit, function, comfort, weight, smell, noise, skin problems, and desire to change to a different prosthesis type.

\section{ANALYSIS}

We analyzed the findings for veterans and servicemembers by type of limb loss: unilateral upper, unilateral lower, and multiple limb loss. In those with multiple limb loss, we analyzed prosthetic-device data for each involved limb. Prosthetic-device data were analyzed for two time intervals: the first year following limb loss and all subsequent years. This article presents data on participants using prostheses at the time they participated in the survey. Our descriptive analysis examined the source(s) of prosthetic care (DOD, VA, private, or multiple sources) for the Vietnam and OIF/OEF groups. Univariate analyses using Stata 9.2 (StataCorp; College Station, Texas) measured overall satisfaction and 21 specific parameters that influence prosthesis satisfaction. Statistical significance (twosided test with $p \leq 0.05$ ) was based on chi-square (categorical data), Mann-Whitney $U$-test (ordinal data), Student $t$-test (continuous data), and Fisher exact test if cell size $\leq 5$. Wilcoxon rank sum scores were used for variables matched on type of limb loss. We computed correlations between specific satisfaction parameters and the overall prosthetic satisfaction ranking for veterans and servicemembers from both conflicts.

\section{RESULTS}

Vietnam participants in our survey averaged 61 years of age, were exclusively male, and were 81 percent Caucasian. The average time since limb loss was 39 years. OIF/OEF participants averaged 29 years of age, 3 percent were female, and 73 percent were Caucasian. No Vietnam veteran participants were on Active Duty. Of the OIF/OEF cohort, 20.5 percent reported being on Active Duty and an additional 8.5 percent were still in rehabilitation more than 1 year after their limb loss. Full- or part-time employment was reported by 79 percent of Vietnam and 54 percent of OIF/OEF participants, with an additional 23 percent of OIF/ OEF participants identified as students. Additional demographic data is reported elsewhere [4]. Overall, 78.2 percent of Vietnam and 90.5 percent of OIF/OEF participants in the survey used their prostheses on a participant-defined "regular basis” (Figure).

\section{Source of Prosthetic Care}

Table 1 shows the source of prosthetic care by conflict. A majority of participants from both conflicts receive care from private sources. In the Vietnam group, VA provides the next highest portion of care, whereas in the OIF/OEF group, nearly 40 percent receive care from DOD.

Thus, private providers under contract with VA were the most common source of prosthetic care for participants from both conflicts.

Table 1 also shows participants' overall prosthesis satisfaction by conflict, level of amputation, and source of care. Satisfaction rankings were uniformly higher for participants receiving private-contract care than those receiving VA care for Vietnam veterans and for OIF/OEF participants with unilateral upper- and lower-limb loss, but not multiple limb loss. The cumulative prosthetic satisfaction score was 7.0 for Vietnam and 7.5 for OIF/OEF.

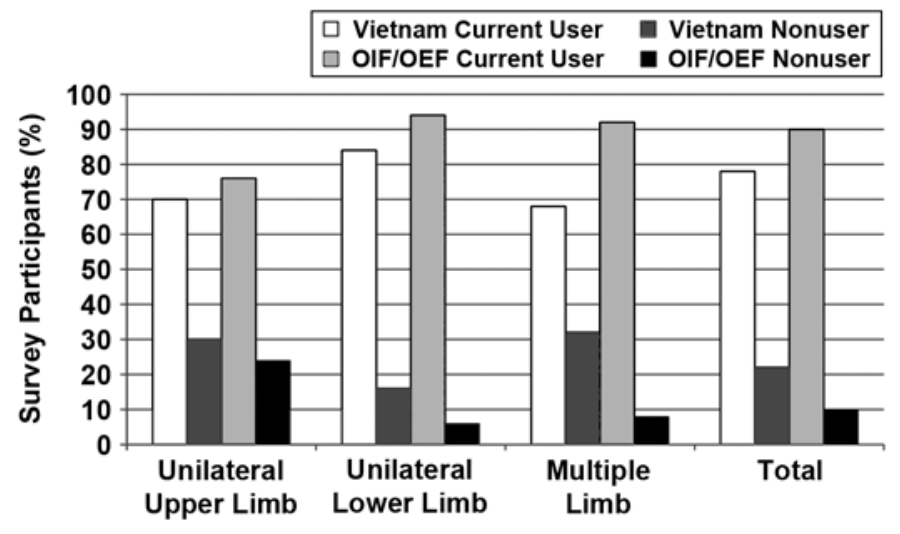

Figure.

Percentage of current prosthetic device users and nonusers by level of limb loss for Vietnam and Operation Iraqi Freedom and Operation Enduring Freedom (OIF/OEF) participants. 
JRRD, Volume 47, Number 4, 2010

Table 2 compares survey participants' satisfaction with their prosthetic care by source of care. Participants were generally able to get an appointment with their prosthetist when needed and were largely satisfied with their training regardless of conflict or source of care. Overall, survey par- ticipants from OIF/OEF reported higher satisfaction with their prosthetic care providers and services than participants from the Vietnam conflict. Less than half of all participants from both conflicts and all sites of service indicated they receive adequate information on new types of prostheses on

Table 1.

Participants' overall mean prosthesis satisfaction ranking ${ }^{*}$ by conflict, level of amputation, and source of care.

\begin{tabular}{|c|c|c|c|c|c|}
\hline Prosthesis Satisfaction & DOD Only & VA Only & Private Only & Multiple Sources $^{\dagger}$ & Total \\
\hline \multicolumn{6}{|l|}{ Vietnam } \\
\hline$n$ & 2 & 37 & 180 & 11 & 230 \\
\hline Unilateral Upper Limb $(n=32)$ & 1.0 & 6.2 & 6.9 & 10 & 6.7 \\
\hline Multiple Limb $(n=49)$ & 10.0 & 5.3 & $6.8^{\ddagger}$ & 9.5 & 6.8 \\
\hline Total $(n=230)$ & 5.5 & 6.2 & $7.1^{\ddagger}$ & 8.1 & 7.0 \\
\hline Unilateral Upper Limb $(n=38)$ & 6.6 & 4.7 & 6.1 & 6.0 & 6.2 \\
\hline Unilateral Lower Limb $(n=158)$ & 7.7 & 6.8 & $7.7^{\ddagger}$ & 8.1 & 7.7 \\
\hline Multiple Limb $(n=55)$ & $7.9^{\ddagger}$ & 8.9 & 8.4 & 6.8 & 7.9 \\
\hline Total $(n=251)$ & 7.5 & 7.0 & 7.6 & 7.5 & 7.5 \\
\hline
\end{tabular}

*Satisfaction ranking from 0 (low) to 10 (high).

${ }^{\dagger}$ Servicemembers may receive prosthetic care from more than one provider source (multiple).

${ }^{\ddagger} p \leq 0.05$ compared with VA source of service.

DOD $=$ Department of Defense, OIF/OEF = Operation Iraqi Freedom/Operation Enduring Freedom, VA = Department of Veterans Affairs.

Table 2.

Overall mean satisfaction ranking of prosthetic services by care source and conflict (reported as percent agreement).

\begin{tabular}{|c|c|c|c|c|c|c|c|c|c|c|}
\hline \multirow[b]{2}{*}{ Care Satisfaction } & \multicolumn{5}{|c|}{ Vietnam } & \multicolumn{5}{|c|}{ OIF/OEF } \\
\hline & $\begin{array}{l}\text { DOD Only } \\
\quad(n=2)\end{array}$ & $\begin{array}{l}\text { VA Only } \\
(n=35)\end{array}$ & $\begin{array}{c}\text { Private } \\
\text { Only } \\
(n=178)\end{array}$ & $\begin{array}{l}\text { Multiple } \\
\text { Sources* }^{*} \\
(n=11)\end{array}$ & $\begin{array}{c}\text { Total } \\
(n=226)\end{array}$ & $\begin{array}{l}\text { DOD Only } \\
(n=95)\end{array}$ & $\begin{array}{l}\text { VA Only } \\
(n=21)\end{array}$ & $\begin{array}{c}\text { Private } \\
\text { Only } \\
(n=104)\end{array}$ & $\begin{array}{l}\text { Multiple } \\
\text { Sources* }^{*} \\
(n=25)\end{array}$ & $\begin{array}{c}\text { Total } \\
(n=245)\end{array}$ \\
\hline $\begin{array}{l}\text { Usually receive appointment with } \\
\text { prosthetist within reasonable amount } \\
\text { of time (initial or repeat visits) }\end{array}$ & 100 & 79 & 88 & 91 & 87 & 89 & 91 & 90 & 84 & 89 \\
\hline $\begin{array}{l}\text { Satisfied with training initially } \\
\text { received on how to use prosthesis }\end{array}$ & 100 & 83 & 82 & 100 & 83 & 97 & 95 & 93 & 92 & 95 \\
\hline $\begin{array}{l}\text { Satisfied with training initially } \\
\text { received on how to maintain } \\
\text { prosthesis }\end{array}$ & 50 & 89 & 82 & 100 & 83 & 92 & 81 & 92 & 76 & 89 \\
\hline $\begin{array}{l}\text { Fully informed about prosthetic } \\
\text { equipment choices }\end{array}$ & 50 & 51 & 58 & 46 & 56 & 78 & 76 & 77 & 80 & 78 \\
\hline $\begin{array}{l}\text { Received adequate information on } \\
\text { new types of prostheses on regular } \\
\text { basis }\end{array}$ & 50 & 29 & 31 & 27 & 31 & 47 & 38 & 48 & 40 & 46 \\
\hline Had role in choosing prosthesis & 50 & 54 & $73^{\dagger}$ & 73 & 70 & 86 & 71 & 86 & 80 & 84 \\
\hline $\begin{array}{l}\text { Interested in trying different type } \\
\text { of prosthesis on trial basis }\end{array}$ & 50 & 80 & 70 & 82 & 72 & 90 & 80 & 93 & 88 & 90 \\
\hline $\begin{array}{l}\text { Want to change current prosthesis } \\
\text { to another type }\end{array}$ & 50 & 60 & $36^{\dagger}$ & 46 & 40 & 41 & 48 & 48 & 52 & 46 \\
\hline
\end{tabular}


a regular basis. Table 2 also shows that significant differences were present among Vietnam veterans in "having a role in choosing my prosthesis," with 73 percent of privatecare participants involved and only 54 percent of VA patients involved. A higher percentage of OIF/OEF participants wanted to try a different type of prosthesis on a trial basis and change their current prosthesis to another type. Also, fewer private-care Vietnam participants indicated they wanted to "change their prosthesis to another type" (60\% VA vs $36 \%$ private, $p \leq 0.05$ ).

\section{Prosthetic Satisfaction by Level of Limb Loss}

The following sections discuss the participants' results specific to prosthetic satisfaction by level of limb loss.

\section{Unilateral Upper-Limb Loss}

Table 3 shows average overall prosthetic satisfaction scores were similar for veterans and servicemembers with unilateral upper-limb loss from both conflicts. Those with more distal transradial limb loss reported higher satisfaction than those with more proximal transhumeral limb loss. Some participants reported that they cannot routinely wear their prosthesis because of a poorly fitting socket (Vietnam 17\%; OIF/OEF 13\%). In those with transhumeral limb loss from the Vietnam group, 29 percent reported being unable to wear their prosthesis because of poor fit. A detailed description of unilateral upper-limb loss and prosthesis use is reported elsewhere [6]. Table 3 also shows only 67 percent of Vietnam and 50 percent of OIF/OEF participants with upper-limb loss were able to wear their prosthesis without pain; however, 75 percent of those with transhumeral limb loss from OIF/OEF reported pain with use of their prosthesis $(p \leq 0.05)$, up significantly from the 43 percent in Vietnam participants. On average, for both conflicts, approximately 40 percent of participants were

Table 3.

Satisfaction issues (reported as percent agreement) with currently used prostheses in Vietnam and OIF/OEF participants with unilateral upperand lower-limb loss by level.

\begin{tabular}{|c|c|c|c|c|c|c|c|c|c|c|c|c|c|c|c|}
\hline \multirow{3}{*}{ Prosthesis Satisfaction } & \multicolumn{7}{|c|}{ Upper Limb } & \multicolumn{8}{|c|}{ Lower Limb } \\
\hline & \multicolumn{3}{|c|}{ Vietnam } & \multicolumn{4}{|c|}{ OIF/OEF } & \multicolumn{4}{|c|}{ Vietnam } & \multicolumn{4}{|c|}{ OIF/OEF } \\
\hline & TR & TH & Total* $^{*}$ & Hand & TR & TH & Total $^{*}$ & Foot & TT & TF & Total $^{\dagger}$ & Foot & $\mathbf{T T}$ & TF & Total $^{\dagger}$ \\
\hline No./Group & 18 & 15 & 33 & 3 & 20 & 15 & 38 & 1 & 112 & 45 & 150 & 6 & 91 & 65 & 162 \\
\hline Average Satisfaction (0-10) & 7.6 & 5.1 & 6.5 & 5.0 & 7.1 & 5.5 & 6.3 & 0 & 7.3 & 7.0 & 7.1 & 7.8 & 7.5 & 7.8 & $7.6^{\ddagger}$ \\
\hline \multicolumn{16}{|l|}{ Satisfaction with prosthesis } \\
\hline Prosthesis fits well & 94 & 50 & 74 & 100 & 100 & $92^{\ddagger}$ & 97 & 0 & 91 & 78 & 87 & 100 & 82 & 89 & 86 \\
\hline Weight of prosthesis is manageable & 94 & 64 & 81 & 100 & 84 & 83 & 85 & 100 & 95 & 93 & 95 & 83 & 94 & 97 & 95 \\
\hline $\begin{array}{l}\text { Want to change current prosthesis } \\
\text { to another type }\end{array}$ & 19 & 29 & 23 & 33 & $42^{\ddagger}$ & $50^{\ddagger}$ & 44 & 100 & 38 & 47 & 41 & 33 & 43 & 43 & 43 \\
\hline \multicolumn{16}{|l|}{ Satisfaction with socket } \\
\hline $\begin{array}{l}\text { Happy with comfort and fit of } \\
\text { socket }\end{array}$ & $87^{\ddagger}$ & 50 & 69 & 100 & 74 & 75 & 76 & 0 & 76 & 69 & 73 & 100 & 73 & 71 & 73 \\
\hline $\begin{array}{l}\text { Cannot wear prosthesis because } \\
\text { socket fits poorly }\end{array}$ & 7 & 29 & 17 & 0 & 11 & 18 & 13 & 100 & 7 & 7 & 8 & 0 & 11 & $15^{\ddagger}$ & 13 \\
\hline \multicolumn{16}{|l|}{ Problems with prosthesis and socket } \\
\hline Prosthesis is pain-free to wear & 75 & 57 & 67 & 33 & 68 & $25^{\ddagger}$ & 50 & 0 & 50 & 47 & 49 & 100 & 61 & 63 & $63^{\ddagger}$ \\
\hline Bothered with skin problems & 35 & 46 & 40 & 33 & 47 & 42 & 44 & 0 & 52 & 60 & 54 & 50 & $72^{\ddagger}$ & 52 & 63 \\
\hline Bothered by noises from prosthesis & 24 & 23 & 23 & 0 & 26 & 17 & 21 & 0 & 40 & 27 & 37 & 33 & 48 & 22 & 37 \\
\hline Bothered with smells from prosthesis & 29 & 15 & 23 & 33 & 32 & 25 & 29 & 0 & 33 & 31 & 33 & 50 & 39 & 31 & 36 \\
\hline $\begin{array}{l}\text { Bothered with sweating inside } \\
\text { socket }\end{array}$ & 53 & 71 & 62 & 100 & 68 & 67 & 70 & 0 & 70 & 67 & 68 & 33 & 57 & 58 & 57 \\
\hline \multicolumn{16}{|l|}{ Coping and adapting } \\
\hline Can cope with prosthesis & 94 & 79 & 87 & 100 & 100 & 83 & 94 & 0 & 94 & 98 & 94 & 100 & 99 & 97 & 98 \\
\hline Have adjusted to life with prosthesis & 94 & 57 & 77 & 100 & 89 & 83 & 88 & 100 & 97 & 100 & 98 & 80 & 98 & 94 & 96 \\
\hline
\end{tabular}


bothered by skin problems, more than 20 percent had prostheses that made bothersome noises, approximately 25 percent were bothered by smells related to the prosthesis, and approximately 66 percent were bothered by sweating in the socket. In spite of these difficulties, 77 percent of Vietnam and 88 percent of OIF/OEF survey participants had adjusted to life with a prosthesis and approximately 90 percent stated they could cope with their prosthesis regardless of conflict and level of amputation.

\section{Unilateral Lower-Limb Loss}

Table 3 shows average prosthetic satisfaction was significantly higher in OIF/OEF than Vietnam participants with unilateral lower-limb loss (7.1 vs 7.6, $p \leq 0.05$ ). Fewer Vietnam veterans with transfemoral limb loss had difficulty wearing their prostheses because of poor socket fit than OIF/OEF veterans ( $7 \%$ vs $15 \%, p \leq 0.05$ ). On average, 87 percent of lower-limb participants in both conflicts reported their prostheses fit well and 95 percent reported a manageable prosthetic weight. Of participants with lowerlimb loss, 73 percent reported that they were happy with their socket comfort and fit and about 40 percent remained interested in changing to another prosthetic type, irrespective of previously noted differences by site of service.

Prosthesis-associated pain was reported as a problem in 51 percent of Vietnam veterans and 37 percent of OIF/OEF participants with unilateral lower-limb loss $(p \leq 0.05)$. Of OIF/OEF respondents, 63 percent reported skin problems on the residual limb compared with 54 percent in the Vietnam group. We should note that a significant increase in skin problems was reported between the OIF/OEF and Vietnam transtibial groups ( $72 \%$ vs $52 \%, p \leq 0.05$ ). Noises, smells, and sweating were common at all levels of unilateral lower-limb loss for both conflict groups. In spite of the difficulties expressed, more than 94 percent of unilateral lower-limb loss participants reported good coping and adapting skills and more than 96 percent stated that they had adjusted to life with a lower-limb prosthesis.

\section{Multiple Limb Loss}

In Table 4, OIF/OEF survey participants with multiple limb loss reported significantly higher overall prosthesis satisfaction scores $(7.9 \pm 1.8)$ than those in the Vietnam group $(6.7 \pm 2.5, p \leq 0.05)$. Socket fit was satisfactory for 80 percent of Vietnam and 89 percent of OIF/OEF participants. Prosthesis-associated pain was reported as a problem in more than one-third of OIF/OEF and Vietnam participants. Of OIF/OEF respondents, 52 percent reported skin
Table 4.

Satisfaction (reported as percent agreement) with currently used prostheses in Vietnam and OIF/OEF participants with multiple limb loss.

\begin{tabular}{|c|c|c|}
\hline Prosthesis Satisfaction & $\begin{array}{l}\text { Vietnam } \\
(n=50)\end{array}$ & $\begin{array}{c}\text { OIF/OEF } \\
(n=56)\end{array}$ \\
\hline $\begin{array}{l}\text { Prosthetic satisfaction (0-10) (mean } \pm \text { SD) } \\
\text { (0) }\end{array}$ & $6.7 \pm 2.5$ & $7.9 \pm 1.8^{*}$ \\
\hline \multicolumn{3}{|l|}{ Satisfaction with prostheses } \\
\hline Prostheses fit well & 86 & 89 \\
\hline Weight of prostheses is manageable & 90 & 98 \\
\hline Want to change current prostheses to another type & 49 & 50 \\
\hline \multicolumn{3}{|l|}{ Satisfaction with socket } \\
\hline Happy with comfort and fit of sockets & 80 & 89 \\
\hline Cannot wear prostheses because sockets fit poorly & 14 & 11 \\
\hline \multicolumn{3}{|l|}{ Problems with prostheses and socket } \\
\hline Prostheses are pain-free to wear & 65 & 61 \\
\hline Bothered with skin problems & 49 & 52 \\
\hline Bothered by noises from prostheses & 41 & 32 \\
\hline Bothered with smells from prostheses & 37 & 43 \\
\hline Bothered with sweating inside sockets & 69 & 71 \\
\hline \multicolumn{3}{|l|}{ Coping and adapting } \\
\hline Can cope with prostheses & 95 & 95 \\
\hline Have adjusted to life with prostheses & 94 & 91 \\
\hline
\end{tabular}

problems on the residual limb compared with 49 percent in the Vietnam group. Noises, smells, and sweating were common at all levels for both conflict groups, with an average of 70 percent of participants reporting being bothered by sweating. Of the Vietnam and OIF/OEF participants, 95 percent stated they could cope with their prosthesis, and more than 90 percent reported that they were adjusting to life with a prosthesis.

\section{Prosthetic Repair and Replacement}

Prosthetic repair and replacement data indicated that approximately 90 percent of participants were able to obtain necessary repairs when needed across all service providers. Slightly lower numbers were reported on getting a prosthetic "replacement" as needed; yet between 67 and 85 percent received replacements when they felt they needed them across all sources of care. Replacement times of $\geq 2$ months (from prescription to initial prosthesis measurement) were reported by 25 percent of the Vietnam group at VA versus 21 percent cared for in private facilities. In the OIF/OEF group, significantly reduced replacement times were noted: 3 percent reported replacement times of $\geq 2$ months at DOD, 15 percent at VA, and 9 percent at private facilities. 


\section{Factors Associated with Prosthetic-Device Satisfaction}

Specific factors were correlated with overall prosthetic-device satisfaction. In both the Vietnam group and the OIF/OEF group, factors that correlated with decreased prosthetic satisfaction included poor socket fit $(p \leq 0.001)$, poor prosthesis fit $(p \leq 0.001)$, difficulty getting repairs or replacements when needed ( $p \leq 0.001$ ), lack of involvement in choosing the type of device ( $\leq 5.001)$, desire to change to another type of prosthetic device $(p \leq 0.001)$, lack of satisfaction with training ( $p \leq 0.01$ for Vietnam participants and $p \leq 0.001$ for OIF/OEF participants), and skin problems ( $p \leq 0.05$ for Vietnam participants and $p \leq 0.001$ for OIF/OEF participants). In addition, in the OIF/OEF group, a high correlation was found between decreased overall prosthesis satisfaction and increased problems with sweat management $(p \leq 0.001)$. Conflict-specific findings did not differ after controlling for age in both conflicts and sex in the OIF/OEF conflict.

\section{DISCUSSION}

Three important improvements were noted in use of prosthetic devices in comparing OIF/OEF and Vietnam veterans with major traumatic limb loss. First, all OIF/ OEF servicemembers with limb loss received care from the DOD Amputee Patient Care Program, including extensive rehabilitation, prostheses, and training, to restore function to the highest level possible. Second, 92 percent of participants with multiple limb loss from the OIF/OEF conflict use prosthetic devices compared with 69 percent from the Vietnam conflict. And third, greater use of prosthetic devices was also noted for OIF/OEF versus Vietnam groups for unilateral lower-limb loss (94\% vs $89 \%$, respectively) and unilateral upper-limb loss (76\% vs $70 \%$, respectively).

Private providers under contract with VA deliver 78 percent of prosthetic devices and related services to Vietnam veterans and 42 percent to OIF/OEF servicemembers and veterans.

Table 1 shows decreased prosthetic satisfaction when VA was compared with private and DOD care, except for participants with unilateral upper-limb loss, for whom satisfaction with prosthetic service providers was similar across conflicts.

Participants with transradial loss were more satisfied overall than those with transhumeral level loss. This is likely due to the difficulty of using transhumeral prosthe- ses and the greater loss of function from the higher level of amputation. Changes in technology did not appear to affect the overall satisfaction in the transhumeral group, despite significant advancements in prosthetic-device technology for this group. These changes in technology include advancements in myoelectric terminal devices, conventional elbow systems, and socket design, as well as in materials and socket suspension. Further, current rehabilitation protocols focus on functional performance training and return to independent function. A related article based on this survey population shows that only 50 percent of all upper-limb survey participants who used myoelectric prostheses used them daily (both Vietnam and OIF/OEF), with even significantly lower daily use reported for hybrid devices (partial myoelectric control and partial body-powered control); yet 59 percent of Vietnam and 68 percent of OIF/OEF participants use a mechanical prosthesis daily [6]. These numbers combined with the fact that little difference in satisfaction was found between the Vietnam and OIF/OEF groups suggest that technological differences with the advent of myoelectric prostheses have had minimal impact on use and overall satisfaction for persons with upper-limb loss. This finding is especially important considering that 30 to 50 percent of all those with upper-limb loss (myoelectric and conventional) have minimal daily prostheticdevice use [6]. Further research is needed to improve function and fit in these high-technology devices.

The average prosthesis-satisfaction score across all lower-limb levels was significantly higher in OIF/OEF participants with unilateral lower-limb loss than Vietnam participants. While most respondents with unilateral lowerlimb loss stated they were satisfied with the fit and comfort of their prostheses, we would hope that changes in materials and technology would positively affect satisfaction for participants at each limb-loss level (i.e., moving the average satisfaction scores into the 8.0 or 9.0 range on a scale of 10). However, this did not appear to be the case. Unilateral lower-limb prosthesis-satisfaction averages were only between 7.0 and 7.8 on a scale of 10 , with no significant differences between participants' level of amputation for both Vietnam and OIF/OEF participants.

In those with multiple limb loss, the OIF/OEF group reported higher overall satisfaction than the Vietnam group, although pain in the residual limbs, skin problems, sweating, and nuisances continued to be frequently reported by all combat-related veterans and servicemembers. 
Vietnam veterans receiving care in the private sector were significantly less likely to want to try different prostheses and components than participants from OIF/OEF receiving private-sector care. It has been reported that as the number of prosthetic-device options increases, the expectation for finding the "perfect" components also increases, leading to ultimate disappointment [8]. This may explain the desire to try new components or prostheses, even in cases in which multiple prostheses and components have been used.

A number of possible reasons exist for the higher overall satisfaction ratings in participants from the OIF/OEF conflict. At the outset is the structure of the initial care and rehabilitation process from the battlefield to rehabilitation care at DOD facilities [9-10]. Also, expansion to multidisciplinary care may affect overall rehabilitation and prosthetic satisfaction. Our survey included OIF/OEF participants who were at least 1 year from limb loss. The factors identified by study participants included their involvement in prosthetic selection, training, and maintenance. A number of advancements to prosthetic materials and components are available to OIF/OEF servicemembers/veterans that were not initially available following the Vietnam era. These may not have been uniformly offered to Vietnam veterans. Additionally, it appears that providing multiple prostheses with different components and allowing each servicemember to meet his or her rehabilitation potential further stimulates involvement in former and new physical activities [5-6,11]. The participants' ages and being greater than 1 year from amputation to survey may affect study findings.

Dillingham et al. studied use and satisfaction with prosthetic devices in people with trauma-related limb loss [12]. They found that prosthetic devices were worn approximately 80 hours per week; yet 57 percent of participants were not satisfied with prosthetic comfort or fit.

In a retrospective cohort study of community participants with limb loss, 25 percent of participants were not satisfied with overall performance of their prostheses and 33 percent were not satisfied with the comfort and fit [13].

Lower-limb prosthetic maintenance, repair, and replacement were reported for individuals in the United Kingdom with more than 10 years of limb-loss experience. Younger participants (age $<60$ ) with transfemoral limb loss needed 1.1 new prostheses, 3.15 new sockets, 4.23 component changes, and 20.49 minor repairs in 10 years. Transtibial participants needed 1.4 new prostheses, 2.9 new sockets, 3.2 major repairs, and 14.1 minor repairs. The authors suggest that prescription of modular prostheses rather than conventional limbs allows easy replacement of components, thus reducing the need for new limbs [14].

In our study, between 25 and 68 percent of participants reported pain-free use of their prostheses (upper and lower limb). The survey did not ask participants to differentiate the frequency, type, and levels of pain. Pain is so prevalent among those with limb loss that it is often underevaluated. According to Kooijman et al., long after surgical wounds have healed, as many as 80 percent of all those with limb loss still experience phantom and residual-limb pain [15]. Since few standardized guidelines exist for evaluating the fit of a prosthesis as it relates to discomfort, the expectation may be that pain, even on an occasional basis, is "normal or acceptable.” Therefore, not only is pain within the residual limb tolerated but also pain associated with use of the prosthetic device is often "tolerated" by the person with limb loss. Pain is a prominent issue for up to half of those who bear weight on a residual limb. One positive finding from this study is that among those with unilateral lower-limb loss, reports of pain with prosthetic use were significantly less in the OIF/OEF group than the Vietnam group. This could be due to overall improved prosthetic fit or surgical techniques.

Findings from other studies report similar pain prevalence. Several of these studies were able to quantify pain to a greater extent than we were able to do in this national survey [16-18]. In Hoaglund et al.'s study, more than 50 percent of those studied with lower-limb amputation had pain in their residual limb with use of their prosthesis [19].

Raichle et al. administered a questionnaire to 752 people with lower-limb loss (average age 54) and 107 with upper-limb loss (average age 47) [20]. Limb-loss etiology was injury for 54 percent of those with lower-limb loss and for 83 percent of those with upper-limb loss. The impact of the prostheses on phantom pain was mixed. Among those with lower-limb loss and phantom pain, pain intensity on a numeric rating scale $(0=$ no pain, $10=$ worst imaginable pain) was between 4.3 and 5.8. About half the participants indicated their prostheses had no effect on phantom pain, 21 percent indicated their prostheses made phantom pain worse, 16 percent reported prostheses lessened phantom pain, and 13 percent did not know if there was an impact. In those with residual-limb pain, 42 percent reported an effect from the prosthesis. In participants with upper-limb loss, pain intensity ranged from 4.4 to 5.8. In these participants, 26 percent indicated their prostheses worsened their phantom pain, 12 percent indicated their prostheses made phantom pain better, 30 percent reported no effect on 
phantom pain, and 32 percent did not know if there was an impact. The survey did not attempt to investigate the methods that participants had used to address their pain issues. Future prospective studies are needed to address the actual and perceived impact of prosthetic use on phantom and residual-limb pain.

In our study, an average of 50 percent of all participants reported skin problems. Persons with lower-limb loss reported higher rates of skin issues than the persons with upper-limb loss. Dillingham et al. reported only 25 percent of all patients with traumatic amputation had problems with wounds, skin irritation, or pain [12]. Dillingham et al. further hypothesized that the skin problems in his study population may have been related to the excessive and repetitive stresses placed on the prostheses by an active population. Other studies find similar incidence of skin problems with prosthetic use [21]. Further investigation of prevention of skin problems is warranted.

This study adds to a growing series of works investigating the satisfaction of people with limb loss as an indicator of quality of care. In this study, survey participants demonstrating lower overall satisfaction also had significant issues with other aspects of their prostheses, further demonstrating that fit and function of the device have a significant impact on overall satisfaction. However, problems with fit are not the only reason for overall participant dissatisfaction. The same people who were less satisfied overall were also more likely to have wanted to change their type of prosthesis, felt they did not have a role in choosing their prosthesis, and had difficulty getting a repair or replacement within a reasonable amount of time. In this study, strong correlations were found between overall satisfaction and issues surrounding fit and delivery systems; however, with no standouts among them, the reasons for overall dissatisfaction appear to be multifactorial.

Several issues were noted surrounding prosthetic selection, training, and information dissemination on new types of prostheses [22]. Research indicates that people who feel well educated about their prosthesis care are more likely to adhere to treatment recommendations and have improved health outcomes [23]. Most individuals receiving care in DOD Amputee Patient Care Centers had multiple opportunities during rehabilitation to trial multiple prosthetic devices. However, a concern across all survey participants was the dearth of information available to individuals with limb loss on new prosthetic devices. The cause for these findings is multifactorial and not entirely clear, especially in light of modern information flow and direct patient component marketing. Agencies caring for these individuals need to identify ways to disseminate appropriate information.

The importance of interdisciplinary rehabilitation teams is increasing [23], and expansion of interdisciplinary care may affect overall rehabilitation and prosthetic use. Work with the newest generation of servicemembers from Iraq and Afghanistan (OIF/OEF) includes those with limb loss in addition to other traumatic injuries, such as fractures, soft tissue and neurological injuries, emerging fragments, thermal burns, heterotopic ossification, and traumatic brain injury [1]. This diverse patient population necessitates improved communication and a multidisciplinary approach to achieve good patient outcomes. Future research addressing age at limb loss and time since limb loss in these settings is needed.

One of the significant limitations of this survey is its inability to differentiate patterns of use. Full-time use may be perceived differently than use of a prosthetic device only for specific tasks or activities. This may require further exploration into a more suitable measure to assess daily patterns of use and the impact of prosthetic satisfaction on daily use patterns. Another limitation is that we were unable to differentiate the cause of participants' pain. While pain may be due to a poorly fitting prosthesis or a perceived poorly fitting prosthesis, it may also be due to a prosthesis in need of a minor adjustment or physiologic pathology, such as a neuroma or scar tissue. Further study of the issues surrounding pain with prosthesis use is required.

Several additional areas require further study. In the upper-limb group, multiple problems were noted with prosthetic fit and function; yet 90 percent reported ability to cope with a prosthesis and 80 percent reported they had adjusted to life with a prosthesis. Similarly, in the lowerlimb group, between 96 and 98 percent reported that they had adjusted to life with a prosthesis; yet up to 15 percent reported their socket fits poorly. Issues of coping and adjustment are complex and warrant further investigation.

\section{CONCLUSIONS}

Prosthetic technology, surgical changes (myodesis, use of wound vac, etc.), and changes in rehabilitation procedures appear to have had little impact on the overall prosthesis satisfaction across those with unilateral upper-limb 
and multiple-limb loss in the Vietnam and OIF/OEF conflicts. Areas of significant concern continue to be socket fit, pain, skin problems, sweating, and nuisances. Formulating appropriate prosthetic prescriptions based on clinical findings and the patient's goals and desires is critical to successful outcomes for servicemembers and veterans with major traumatic limb loss. Important differences were found in the overall satisfaction between sources of prosthetic care; however, these differences appear to be more profound when compared across conflict than between sources within the same conflict group. Differences in prosthetic satisfaction between sources of care suggest a need for continued practitioner education and system evaluation. Multiple opportunities exist for prosthetic providers in all settings to improve care.

\section{ACKNOWLEDGMENTS}

\section{Author Contributions:}

Study concept and design: G. M. Berke, J. Fergason, J. R. Milani, J. Hattingh, M. McDowell, V. Nguyen, G. E. Reiber.

Data analysis and interpretation: G. M. Berke, J. Fergason,

J. R. Milani, J. Hattingh, M. McDowell, V. Nguyen, G. E. Reiber.

Drafting of manuscript: G. M. Berke, J. Fergason, J. R. Milani,

J. Hattingh, M. McDowell, V. Nguyen, G. E. Reiber.

Critical revision of manuscript for important intellectual content:

G. M. Berke.

Statistical analysis: G. M. Berke, G. E. Reiber.

Administrative support: G. E. Reiber.

Funding/study supervision: G. E. Reiber.

Financial Disclosures: The authors have declared that no competing interests exist.

Funding/Support: This material was based on work supported by the VA Health Services Research and Development Service (grant IIR 05244) and a Career Scientist Award to Dr. Reiber (grant RCS 98-353). The views expressed in this article are those of the authors and do not necessarily reflect the position or policy of VA or DOD.

Additional Contributions: We sincerely thank the veterans and servicemembers who participated in our survey.

Institutional Review: Institutional and human subjects' approvals were received from VA and DOD. A waiver of consent was obtained for survey participants.

Participant Follow-Up: Each study participant will receive a copy of this single-topic issue of $J R R D$.

\section{REFERENCES}

1. Pasquina PF, Tsao JW, Collins DM, Chan BL, Charrow A, Karmarkar AM, Cooper RA. Quality of medical care provided to service members with combat-related limb amputations: Report of patient satisfaction. J Rehabil Res Dev.
2008;45(7):953-60. [PMID: 19165685]

DOI:10.1682/JRRD.2007.10.0163

2. Facility accreditation [Internet]. Alexandria (VA): American Board for Certification in Orthotics, Prosthetics \& Pedorthics; 2009 [cited 2009 Jul 16]. Available from: http://abc.oandp.com/Facility_Accreditation.asp/.

3. BOC Certification \& Certificate Programs [Internet]. Owings Mills (MD): Board of Certification/Accreditation, International; 2009 [cited 2009 Jul 16]. Available from: http://www.bocusa.org/BOC.cfm?Page=28/.

4. Reiber GE, McFarland LV, Hubbard S, Maynard C, Blough DK, Gambel JM, Smith DG. Servicemembers and veterans with major traumatic limb loss from Vietnam war and OIF/ OEF conflicts: Survey methods, participants, and summary findings. J Rehabil Res Dev. 2010;47(4):275-98.

5. Gailey R, McFarland LV, Cooper RA, Czerniecki J, Gambel JM, Hubbard S, Maynard C, Smith DG, Raya M, Reiber GE. Unilateral lower-limb loss: Prosthetic device use and functional outcomes in servicemembers from Vietnam war and OIF/OEF conflicts. J Rehabil Res Dev. 2010;47(4):317-32.

6. McFarland LV, Hubbard Winkler SL, Heinemann AW, Jones M, Esquenazi A. Unilateral upper-limb loss: Satisfaction and prosthetic-device use in veterans and servicemembers from Vietnam and OIF/OEF conflicts. J Rehabil Res Dev. 2010; 47(4):299-316.

7. Laferrier JZ, McFarland LV, Boninger ML, Cooper RA, Reiber GE. Wheeled mobility: Factors influencing mobility and assistive technology in veterans and servicemembers with major traumatic limb loss from Vietnam war and OIF/ OEF conflicts. J Rehabil Res Dev. 2010;47(4):349-60.

8. Schwartz B. The paradox of choice: Why more is less [Internet]. New York (NY): TED: Ideas worth spreading; 2006 [cited 2009 Mar 19]. Available from:

http://www.ted.com/index.php/talks/ barry schwartz on the paradox of choice.html.

9. Gajewski D, Granville R. The United States Armed Forces Amputee Patient Care Program. J Am Acad Orthop Surg. 2006;14(10 Spec No.):S183-87. [PMID: 17003196]

10. Gawande A. Casualties of war-Military care for the wounded from Iraq and Afghanistan. N Engl J Med. 2004; 351(24):2471-45. [PMID: 15590948$]$

11. Dougherty PJ, McFarland LV, Smith DG, Esquenazi A, Blake DJ, Reiber GE. Multiple traumatic limb loss: A comparison of Vietnam veterans to OIF/OEF servicemembers. J Rehabil Res Dev. 2010;47(4):333-48.

12. Dillingham TR, Pezzin LE, MacKenzie EJ, Burgess AR. Use and satisfaction with prosthetic devices among persons with trauma-related amputations: A long-term outcome study. Am J Phys Med Rehabil. 2001;80(8):563-71. [PMID: 11475475] DOI:10.1097/00002060-200108000-00003

13. Pezzin LE, Dillingham TR, Mackenzie EJ, Ephraim P, Rossbach P. Use and satisfaction with prosthetic limb devices and 
related services. Arch Phys Med Rehabil. 2004;85(5):723-29. [PMID: 15129395]

DOI:10.1016/j.apmr.2003.06.002

14. Nair A, Hanspal RS, Zahedi MS, Saif M, Fisher K. Analyses of prosthetic episodes in lower limb amputees. Prosthet Orthot Int. 2008;32(1):42-49. [PMID: 17943622] DOI:10.1080/03093640701610615

15. Kooijman CM, Dijkstra PU, Geertzen JH, Elzinga A, Van der Schans CP. Phantom pain and phantom sensations in upper limb amputees: An epidemiological study. Pain. 2000;87(1): 33-41. [PMID: 10863043] DOI:10.1016/S0304-3959(00)00264-5

16. Czerniecki JM, Ehde DM. Chronic pain after lower extremity amputation. Crit Rev Phys Med Rehabil. 2003; 5(3-4):70.

17. Ketz AK. The experience of phantom limb pain in patients with combat-related traumatic amputations. Arch Phys Med Rehabil. 2008;89(6):1127-32. [PMID: 18503810] DOI:10.1016/j.apmr.2007.11.037

18. Jensen MP, Smith DG, Ehde DM, Robinsin LR. Pain site and the effects of amputation pain: Further clarification of the meaning of mild, moderate, and severe pain. Pain. 2001; 91(3):317-22. [PMID: 11275389] DOI:10.1016/S0304-3959(00)00459-0
19. Hoaglund FT, Jergesen HE, Wilson L, Lamoreux LW, Roberts R. Evaluation of problems and needs of veteran lowerlimb amputees in the San Francisco Bay Area during the period 1977-1980. J Rehabil Res Dev. 1983;20(1):57-71. [PMID: 6887067]

20. Raichle KA, Hanley MA, Molton I, Kadel NJ, Campbell K, Phelps E, Ehde D, Smith DG. Prosthesis use in persons with lower- and upper-limb amputation. J Rehabil Res Dev. 2008;45(7):961-72. [PMID: 19165686] DOI:10.1682/JRRD.2007.09.0151

21. Koc E, Tunca M, Akar A, Erbil AH, Demiralp B, Arca E. Skin problems in amputees: A descriptive study. Int J Dermatol. 2008;47(5):463-66. [PMID: 18412862]

DOI:10.1111/j.1365-4632.2008.03604.X

22. Van der Linde H, Hofstad CJ, Geertzen JH, Postema K, Van Limbeek J. From satisfaction to expectation: The patient's perspective in lower limb prosthetic care. Disabil Rehabil. 2007;29(13):1049-55. [PMID: 17612990] DOI:10.1080/09638280600948375

23. Nielsen CC. A survey of amputees: Functional level and life satisfaction, information needs, and the prosthetist's role. J Prosthet Orthot. 1991;3(3):125-29.

Submitted for publication December 3, 2009. Accepted in revised form April 7, 2010. 
